\title{
Birth Weight and Nutrient Restriction Affect Jejunal Enzyme Activity and Gene Markers for Nutrient Transport and Intestinal Function in Piglets
}

\author{
Michael O. Wellington ${ }^{1,2,+} \mathbb{C}$, Lucas A. Rodrigues ${ }^{1,2}$, Qiao Li ${ }^{3}$, Bingqi Dong ${ }^{3}$, Josiane C. Panisson ${ }^{1,2}$, \\ Chengbo Yang ${ }^{3}(\mathbb{D})$ and Daniel A. Columbus $1,2, * \mathbb{D}$ \\ 1 Prairie Swine Centre, Inc., Saskatoon, SK S7H 5N9, Canada; michael.wellington@usask.ca (M.O.W.); \\ lucas.rodrigues@usask.ca (L.A.R.); josiane.panisson@usask.ca (J.C.P.) \\ 2 Department of Animal and Poultry Science, University of Saskatchewan, Saskatoon, SK S7N 5A8, Canada \\ 3 Department of Animal Science, University of Manitoba, Winnipeg, MB RT3 2N2, Canada; \\ liqiao2017hzau@163.com (Q.L.); bingqi.dong@umanitoba.ca (B.D.); chengbo.yang@umanitoba.ca (C.Y.) \\ * Correspondence: dan.columbus@usask.ca \\ † Present address: Trouw Nutrition R\&D Swine, Stationsstraat 77, 3811 MH Amersfoort, The Netherlands.
}

Citation: Wellington, M.O.;

Rodrigues, L.A.; Li, Q.; Dong, B.;

Panisson, J.C.; Yang, C.; Columbus,

D.A. Birth Weight and Nutrient

Restriction Affect Jejunal Enzyme

Activity and Gene Markers for

Nutrient Transport and Intestinal

Function in Piglets. Animals 2021, 11,

2672. https://doi.org/10.3390/

ani11092672

Received: 28 July 2021

Accepted: 9 September 2021

Published: 11 September 2021

Publisher's Note: MDPI stays neutral with regard to jurisdictional claims in published maps and institutional affiliations.

Copyright: (c) 2021 by the authors. Licensee MDPI, Basel, Switzerland. This article is an open access article distributed under the terms and conditions of the Creative Commons Attribution (CC BY) license (https:/ / creativecommons.org/licenses/by/ $4.0 /)$.
Simple Summary: Birth weight and nutrient utilization are thought to have significant effects on intestinal development in neonatal pigs. The present study evaluated the impact of low and normal birth weight with and without nutrient restriction during the neonatal period on jejunal development. The results observed suggest that during the first $28 \mathrm{~d}$ of life, birth weight had greater effects on intestinal development than nutrient level, however, at $d 56$, the nutrient level was a significant contributor to intestinal function and enzyme activity compared to birth weight. Taken together, both birth weight and nutrient restriction have effects on intestinal development, but may have a greater impact in early life (d 28).

Abstract: Significant variation in the birth weight of piglets has arisen due to increased sow prolificacy. Intestinal development and function may be affected by birth weight. Low birth weight (LBW) pigs may also have reduced feed intake, leading to further impairment of intestinal development. The objective of this study was to examine the intestinal development pattern of LBW and normal birth weight (NBW) piglets with normal nutrition (NN) or restricted nutrition (RN) in the pre-weaning period. Jejunal intestinal samples were analyzed for target gene expression and enzyme activity at d 28 (weaning) and d 56 (post-weaning). At d 28, excitatory amino acid transporter (EAAC1) and sodium-dependent neutral amino acid transporter $\left(\mathrm{B}^{0} \mathrm{AT} 1\right)$ were downregulated in LBW compared to NBW pigs $(p<0.05)$. On d 56, $\mathrm{B}^{0} \mathrm{AT} 1$ and ASCT2 (glutamine transporter) were downregulated in RN compared to NN pigs ( $p<0.05$ ), regardless of birth weight. Peptide transporter 1 (PepT1) expression was downregulated in LBW compared to NBW pigs at $28 \mathrm{~d}(p<0.05)$, with no effects of treatments at $56 \mathrm{~d}$. Sodium-glucose transporter-1 (SGLT1) was upregulated in NBW-NN compared to LBW-NN pigs $(p<0.05)$ at $28 \mathrm{~d}$. Alkaline phosphatase (ALP) was upregulated in LBW-RN at d 28. At d 56, claudin-3 (CLDN-3) and Zonular occludin-1 (ZO-1) were upregulated in NN compared to RN pigs $(p<0.05)$. There were no treatment effects on ALP, maltase, or sucrase activity at $28 \mathrm{~d}$. However, at $56 \mathrm{~d}$, ALP was upregulated in NBW-NN pigs while sucrase activity was upregulated in NN pigs $(p<0.05)$. The results demonstrate differences in jejunal gene expression associated with birth weight, with reduced gene expression of amino acid transporters (PepT1, EAAC1, $\mathrm{B}^{0} \mathrm{AT} 1$ ) in LBW compared to NBW pigs $(p<0.05)$. While neonatal nutrient restriction had minimal effects at $28 \mathrm{~d}$ and $\mathrm{d} 56$ for tight junction protein transcript abundance, neutral amino acid transporter abundance was upregulated in NN pigs compared to RN piglets $(p<0.05)$.

Keywords: low birth weight; normal birth weight; neonatal piglets; intestinal development; gene expression; normal nutrition; restricted nutrition 


\section{Introduction}

There is significant variation in the birth weight of piglets within the same litter, which is primarily related to an increase in sow prolificacy (i.e., increased litter size) [1,2]. The survival and development of neonatal piglets are associated with birth weight [3,4], with piglets born at low birth weight (LBW) at higher risk of poor growth and development, including inadequate intestinal development and function. For example, Tao et al. [5] investigated the effects of birth weight on the gastrointestinal barrier function of pigs at $90 \mathrm{~d}$ of age and reported increased intestinal damage, decreased antioxidant capacity, increased abundance of proinflammatory cytokines, and inhibition of tight junction proteins expression in LBW compared to normal birth weight (NBW) pigs. Moreover, it has been shown that the maturation of digestive function was delayed in LBW pigs, regardless of the stress associated with weaning transition [6]. In addition to their small size, LBW piglets may have reduced access to nutrition in the pre-weaning period due to competition with larger littermates $[7,8]$, potentially exacerbating the negative effects of LBW on intestinal function, as sufficient nutrient intake is critical for intestinal development [9]. Inadequate intestinal development will lead to short- and long-term complications, including poor nutrient digestion and absorption, reduced intestinal barrier function, and increased susceptibility to pathogens $[10,11]$, as well as reduced overall animal performance (i.e., growth). While the development of neonatal pigs has been widely studied, the independent and interactive effects of birth weight and nutrient restriction on intestinal development are not well known.

We previously developed and validated a model of birth weight and neonatal undernutrition, which demonstrated a modified intermittent suckling protocol as an effective strategy to induce nutrient restriction in pigs [12]. Since our model identified major differences in performance and organ development at $56 \mathrm{~d}$, as influenced by birth weight category (BWC) but not neonatal nutrient restriction, it is important to understand the specific effects of BWC and nutrient restriction on intestinal development and function.

Therefore, the objective of this study was to examine jejunal enzyme activity and gene expression of nutrient transporters and indicators of intestinal barrier function in LBW and NBW piglets with either normal pre-weaning nutrition $(\mathbf{N N})$ or restricted nutrition $(\mathbf{R N})$ on jejunal gene expression and enzyme activity. We hypothesized that both LBW and NR would negatively affect intestinal development and function.

\section{Materials and Methods}

The protocols used in this study were approved by the Animal Research Ethics Board of the University of Saskatchewan (Animal Use Protocol \#20190042) and followed the Canadian Council of Animal Care guidelines for the care and use of farm animals in research.

\subsection{Animals, Housing, and Experimental Design}

Details of the experimental procedure have been outlined previously [12]. Briefly, a total of 14 sows and 112 piglets (Camborough Plus $\times$ C3378; PIC Canada Ltd., Winnipeg MB, Canada) were housed in farrowing crates at the Prairie Swine Centre (Saskatoon, SK, Canada) over 4 blocks (farrowing group) and fed a common commercial lactation diet (Masterfeeds, Saskatoon, SK, Canada). After farrowing, all piglets in the litter were individually weighed and identified as LBW or NBW based on previously established weight ranges in this population of pigs [13], with piglets of $<1.5 \mathrm{~kg}$ initial body weight considered LBW. Postnatal nutrient restriction (RN) was induced in 4 target piglets per litter ( 2 LBW and 2 NBW, balanced for sex) through isolation from the sow for $6 \mathrm{~h} / \mathrm{d}$ from $0800-1400 \mathrm{~h}$ from $\mathrm{d} 3$ post-farrowing to weaning ( $\mathrm{d} 28)$, based on a modification of previously described methods [14,15]. All other piglets were allowed unrestricted access to the sow [normal nutrition $(\mathrm{NN})$ ]. No additional feed was provided to the piglets before weaning. At the end of the $28-\mathrm{d}$ suckling period, piglets were weaned and housed in groups of 3-6/pen and fed a common commercial nursery diet (Masterfeeds) from d 29-56 
post-weaning. At d 28 and 56 of the study, 8 piglets /treatment ( 2 piglets /treatment per block) were randomly selected (balanced for sex) and euthanized with an overdose of isoflurane (oxygen flow at $1 \mathrm{~L} / \mathrm{min}$ with $5 \%$ isoflurane) followed by exsanguination. After evisceration, sections of the small intestine (jejunum) were sampled and immediately snapfrozen in liquid nitrogen and then stored at $-80{ }^{\circ} \mathrm{C}$ until analysis. In all, a total of 16 piglets were euthanized for each treatment ( 8 piglets /treatment on $\mathrm{d} 28$ and 8 piglets/treatment on $\mathrm{d}$ 56) for a total of 64 piglets.

\subsection{Enzyme Activity Assay}

The enzyme activities of intestinal digestive enzymes including intestinal alkaline phosphatase (ALP), maltase, and sucrase were determined. Briefly, approximately $500 \mathrm{mg}$ of pulverized and frozen jejunal tissue samples were thawed in an ice-cold homogenizing buffer consisting of $50 \mathrm{mM}$ D-mannitol and $0.1 \mathrm{mM}$ phenylmethylsulphonyl fluoride (PMSF) at pH 7.4 (Sigma-Aldrich Chemical Co., St. Louis, MO, USA) and homogenized on ice using a polytron homogenizer (Fisher Scientific, Ottawa, ON, Canada). After centrifugation ( $4000 \mathrm{rpm}, 10 \mathrm{~min}, 4^{\circ} \mathrm{C}$ ), the protein concentrations of the homogenate suspensions were determined using a Bicinchoninic acid Protein Assay kit (Thermo Fisher Scientific, Waltham, MA, USA). Alkaline phosphatase (EC. 3.4.11.2) activity was assayed according to the method of Engström [16]. Potassium fluoride (Sigma-Aldrich Chemical Co.) was added to inhibit the interference of intracellular acid phosphatase in the intestinal mucosa [17]. Incubations were conducted in a final volume of $0.50 \mathrm{~mL}$ containing homogenized tissue suspensions (0.100 to $0.200 \mathrm{mg}$ protein), $2.0 \mathrm{mM}$ potassium fluoride, $5.0 \mathrm{mM} \mathrm{MgCl}_{2}$, and $40.0 \mathrm{mM}$ p-nitrophenyl phosphate (Sigma-Aldrich Chemical Co.) at $\mathrm{pH} 10.5$ for $15 \mathrm{~min}$ at $37^{\circ} \mathrm{C}$. The enzyme reaction was stopped by adding $0.50 \mathrm{~mL}$ of $0.50 \mathrm{M} \mathrm{NaOH}$ (Sigma-Aldrich Chemical Co.). The end-product of the enzyme reaction, p-nitrophenol, was measured using a Synergy ${ }^{\mathrm{TM}} \mathrm{H} 4$ Hybrid Multi-Mode Microplate Reader (BioTek, Winooski, VT, USA) at $400 \mathrm{~nm}$ wavelength. Maltase (E.C. 3.2.1.20) and sucrase (E.C. 3.2.1.48) activities were assayed according to a previously established method [18]. Incubations were conducted in a final volume of $0.500 \mathrm{~mL}$ containing homogenized cell suspensions ( 0.200 to $0.300 \mathrm{mg}$ protein), $100 \mathrm{mM}$ maleate buffer (maleic acid dissolved in $\mathrm{NaOH}$ ), and $60 \mathrm{mM}$ maltose, $60 \mathrm{mM}$ sucrose, or $100 \mathrm{mM}$ amylose, at $\mathrm{pH} 6.0$ and $37^{\circ} \mathrm{C}$ for $20 \mathrm{~min}$. Incubations were terminated by adding $70 \mathrm{mM} \mathrm{ZnSO}_{4}$. The end-product of both enzyme reactions, D-glucose (Pointe Scientific, Inc., Canton, MI, USA), was measured by spectrophotometric analysis at $500 \mathrm{~nm}$. All enzyme assays were corrected for nonspecific blank readings.

\subsection{Real-Time Polymerase Chain Reaction ( $q-P C R$ )}

Tissue samples stored at $-80{ }^{\circ} \mathrm{C}$ were ground in liquid nitrogen with mortar and pestle and total RNA of the jejunum tissue was extracted by the Trizol reagent procedure (Invitrogen, Carlsbad, CA, USA) according to the manufacturer's instructions. Total RNA was dissolved in $20 \mu \mathrm{L}$ RNase-free water and concentration was determined using a NanoDrop 2000 spectrophotometer (Nano-Drop Technologies, Wilmington, DE, USA) with purity ascertained (A260/ A280) between 1.8 and 2.0. The total RNA (about $1 \mu \mathrm{g}$ ) from each sample was reversed transcribed into cDNA using iScript cDNA Synthesis Kit (Bio-Rad, Mississauga, ON, Canada) according to the manufacturer's instructions with a random hexamer primer. Each $20 \mu \mathrm{L}$ of reaction mix consisted of $0.8 \mu \mathrm{L}$ of $10 \mu \mathrm{mol} / \mathrm{L}$ primer concentration for each forward and reverse primer, $6.4 \mu \mathrm{L}$ of nuclease-free water, $10 \mu \mathrm{L}$ of EVA green supermix (Bio-Rad Laboratories, Hercules, CA, USA) and $2 \mu \mathrm{L}$ ( 2 ng / qPCR reaction) of template cDNA. Standard curves were made for each gene using a 5-fold serial dilution of pooled cDNA samples from all experimental treatments. A PCR efficiency between $90 \%$ and $110 \%$ was accepted as valid for data analysis. The qPCR analysis was performed to quantify the target genes encoding for enzyme (ALP, SI), nutrient transporter (SGLT1, PepT1, EAAC1, ASCT2), and $\left.\mathrm{B}^{0} \mathrm{AT} 1\right)$, and barrier function genes (ZO-1 and Claudin-3), as presented in Table 1. The cyclophilin-A (Cyc-A) gene was used as the 
housekeeping gene. The relative changes in gene expression levels of genes in the jejunum tissues normalized against $\mathrm{Cyc}-\mathrm{A}$ were determined by using the $2^{-\Delta \Delta \mathrm{CT}}$ method according to Livak and Schmitten [19].

Table 1. The primer sequences of the target genes and the internal reference gene.

\begin{tabular}{|c|c|c|c|}
\hline Gene Name & Sequence $\left(5^{\prime}-3^{\prime}\right)$ & Accession Number & Product Size (bp) \\
\hline \multirow{3}{*}{$A L P$} & Enzyme genes & & \\
\hline & F: CCACTCCGCGCCACC & XM_021097682.1 & 76 \\
\hline & R: AAGAGCTCGTGGGTGAAGG & & \\
\hline \multirow[t]{2}{*}{$S I$} & F: TGATAGGCCAGTGAGAGTGC & XM_021069748.1 & 99 \\
\hline & R: AGAGTTGAGTAAGGCTGCCA & & \\
\hline \multirow{3}{*}{ SGLT1 } & Nutrient transporter genes & & \\
\hline & F: GGCTGGACGAAGTATGGTGT & NM_001164021.1 & 153 \\
\hline & R: ACAACCACCCAAATCAGAGC & & \\
\hline \multirow{2}{*}{$E A A C 1$} & F: GTTCCTGATTGCCGGGAAGA & NM_001164649.1 & 165 \\
\hline & R: ATGGCGAATCGGAAAGGGTT & & \\
\hline \multirow[t]{2}{*}{ ASCT2 } & F: GCCAGCAAGATTGTGGAGAT & XM_003355984.4 & 206 \\
\hline & R: GAGCTGGATGAGGTTCCAAA & & \\
\hline \multirow[t]{2}{*}{$B^{0} A T 1$} & F: AAGGCCCAGTACATGCTCAC & XM_0033559855.4 & 102 \\
\hline & R: CATAAATGCCCCTCCACCGT & & \\
\hline \multirow[t]{2}{*}{ PepT1 } & F: CATCGCCATACCCTTCTG & NM_214347.1 & 143 \\
\hline & R: TTCCCATCCATCGTGACATT & & \\
\hline \multirow{3}{*}{$\mathrm{ZO}-1$} & Barrier function genes & & \\
\hline & F: GATCCTGACCCGGTGTCTGA & XM_021098896.1 & 200 \\
\hline & R: TTGGTGGGTTTGGTGGGTT & & \\
\hline \multirow{2}{*}{ CLDN3 } & F: CTACGACCGCAAGGACTACG & NM_001160075.1 & 123 \\
\hline & R: TAGCATCTGGGTGGACTGGT & & \\
\hline \multirow{3}{*}{$C y c A$} & Internal reference gene & & \\
\hline & F: GCGTCTCCTTCGAGCTGTT & NM_214353.1 & 160 \\
\hline & R: CCATTATGGCGTGTGAAGTC & & \\
\hline
\end{tabular}

ALP; alkaline phosphatase, SI; sucrase-isomaltase, SGLT1; sodium/glucose cotransporter 1, EAAC1; excitatory amino acid transporter 1, ASCT2; glutamine transporter, $\mathrm{B}^{0}$ AT1; sodium-dependent neutral amino acid transporter, PepT1; peptide transporter 1, ZO-1; zonula occludens-1, CLDN3; claudin 3, CycA; Cyclophilin-A.

\subsection{Statistical Analysis}

Data were tested for normality and outliers using the PROC UNIVARIATE model and the Shapiro-Wilk test in SAS version 9.4 (SAS Institute Inc., Cary, NC, USA). Outliers were determined as a value \pm 2 standard deviations away from the treatment mean using the studentized residual analysis. Data were analyzed using the MIXED procedure of SAS with different groups of piglets sampled on d 28 and d 56, analyzed separately as a randomized complete block design with a $2 \times 2$ factorial arrangement. The fixed effects were (1) birth weight category (BWC) (LBW and NBW), (2) dietary treatment (RN and $\mathrm{NN}$ ), and (3) their interaction. Block (farrowing group) was included in the model as a random effect. Initially, sex was also included as a fixed effect but was not significant and, therefore, removed from the model. Differences between treatment means were separated by the PDIFF option adjusted for the Tukey test. Significance differences were determined at $p \leq 0.05$ and a trend toward significance was considered at $p<0.10$.

\section{Results}

\subsection{Enzyme Activity}

Enzyme activity results are reported in Figure 1, with the foremost panel showing ALP, maltase, and sucrase at d 28 and the other panel showing results for $\mathrm{d} 56$. On $\mathrm{d} 28$, there were no significant effects of treatment on any of the measured parameters. On $\mathrm{d} 56$, there was an interaction between birth weight and nutrient restriction, with the NBW-NN group having greater ALP activity compared to the other treatments $(p<0.05)$. Further, we 
observed a nutrition level effect on sucrase activity where NN piglets had a significantly higher sucrase activity compared to RN ( 54.3 vs. 39.9; $p<0.05)$ regardless of BWC. There were no other treatment effects on any other measured enzyme activity.
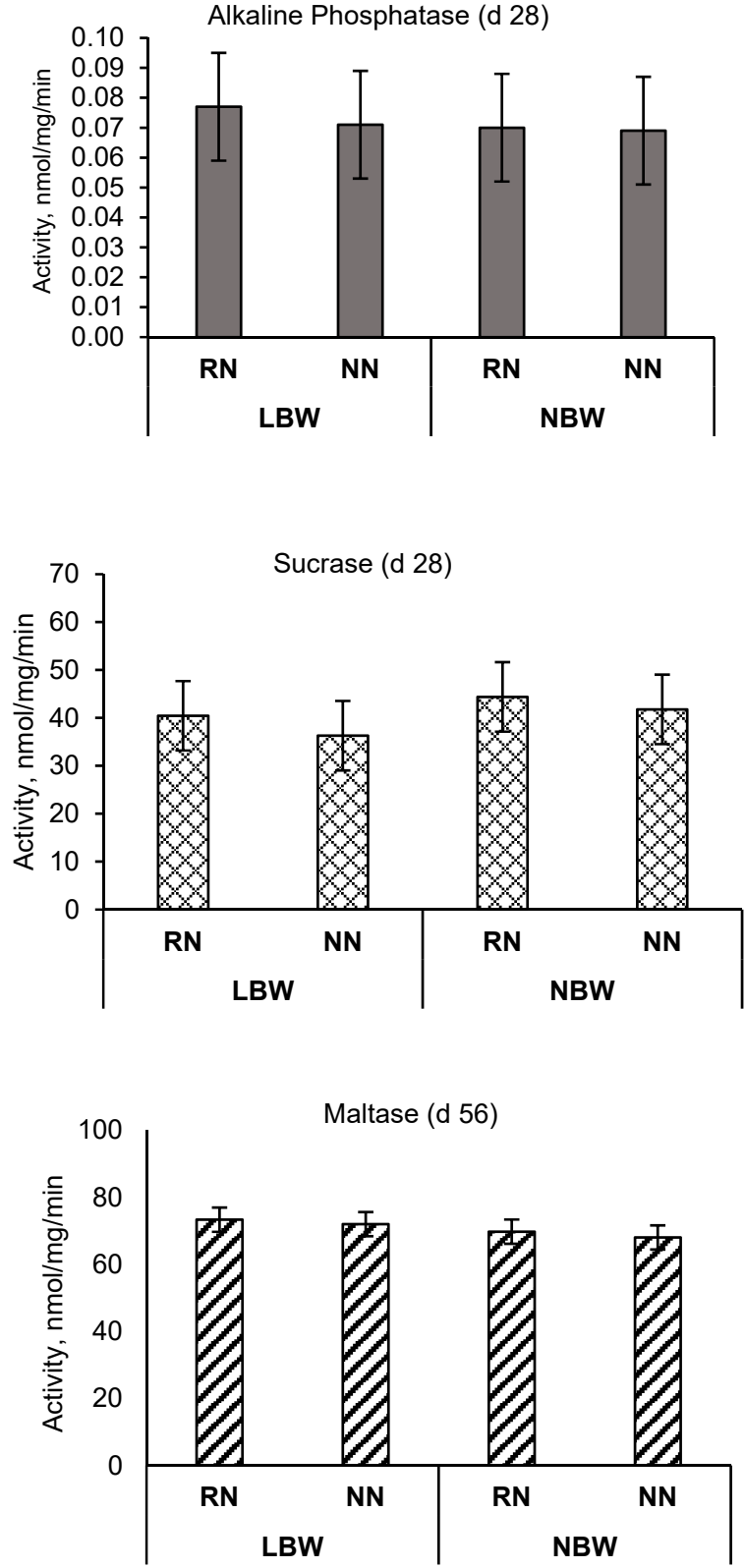

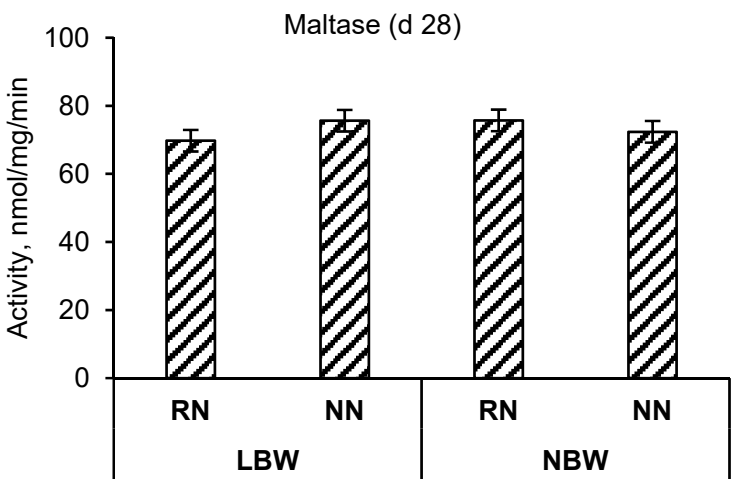

Alkaline Phosphatase (d 56)

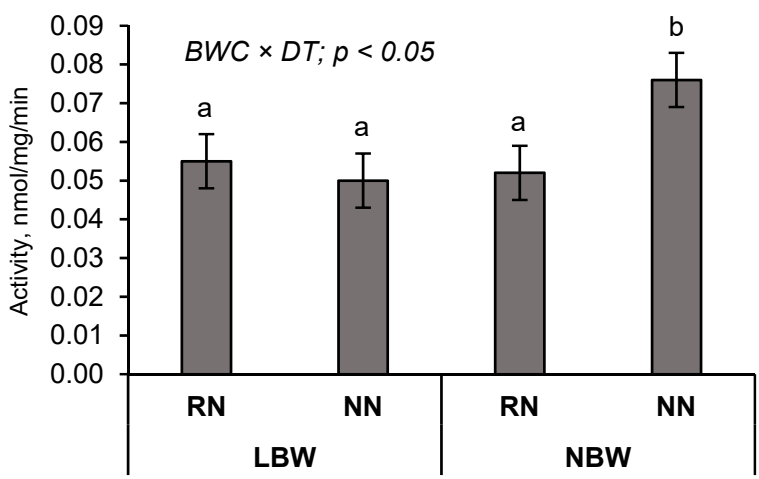

Sucrase (d 56)

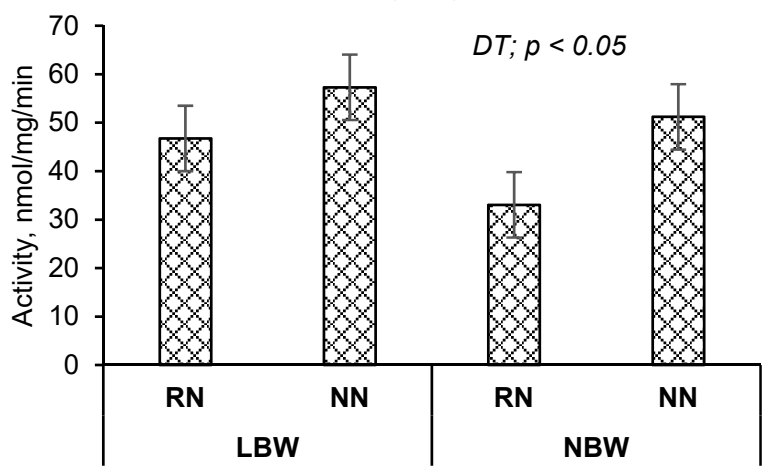

Figure 1. Enzyme activity in jejunal tissue for piglets d 28 and d 56 post-weaning. LBW; Low birth weight, NBW; normal birth weight, RN; restricted nutrition; NN; normal nutrition, BWC; birth weight category, DT; dietary treatment. $\mathrm{a}, \mathrm{b}$ Lowercase superscripts are indicative of a significant interaction. There was a significant main effect of dietary treatment (NN vs. RN) on sucrase activity 54.3 vs. $39.9(p<0.05)$.

\section{2. $R T-q P C R$ of Target Genes}

Tables 2 and 3 show target gene expression of jejunal tissue samples of piglets at 28 and $56 \mathrm{~d}$, respectively. At weaning (d28), piglets within the NBW category had a significantly higher expression of EAAC1 (3.54 vs. 1.48), $\mathrm{B}^{0} \mathrm{AT} 1$ (2.28 vs. 1.12), and PepT1 (2.56 vs. 1.27) compared to piglets with LBW $(p<0.05)$, with no effect of nutrient restriction at either time point. Further, ZO1, Claudin-3, SI, and ASCT2 were not affected by birth weight or nutrition level. The expression of SGLT1 and ALP was significantly affected by the 
interaction of birth weight and nutrition level. Specifically, ALP expression was higher in LBW-RN pigs compared to LBW-NN and NBW-RN pigs $(p<0.05)$ but equal to NBW-NN pigs. Expression of SGLT1 was reduced in the LBW-NN compared to NBW-NN pigs $(p<0.05)$ and equal to other treatment groups. At d 56, there were no significant treatment effects on SGLT1, PepT1 or EAAC1. Generally, at d 56, there was a significant effect of the nutrient restriction group (NN vs. RN) on Claudin-3, ZO1, ASCT1, and $\mathrm{B}^{0} \mathrm{AT} 1$. Specifically, $\mathrm{NN}$ piglets, regardless of BWC, had greater expression of Claudin-3 (1.84 vs. 0.60), ZO1 ( 2.70 vs. 0.51 ), ASCT1 (2.27 vs. 0.34 ), and $\mathrm{B}^{0} \mathrm{AT} 1$ (3.62 vs. 0.97$)$ compared to RN piglets $(p<0.01)$. There was a significant interaction between BWC and nutrition on ALP and SI expression. Specifically, there was increased expression of ALP and SI in NBW-NN piglets compared to all other treatments $(p<0.05)$.

Table 2. Jejunal nutrient transporter and tight junction mRNA transcript abundance at $28 \mathrm{~d}$ post-weaning.

\begin{tabular}{ccccccccc}
\hline & \multicolumn{2}{c}{ LBW } & \multicolumn{2}{c}{ NBW } & \multicolumn{3}{c}{$p$-Value } \\
\hline Genes & RN & NN & RN & NN & SEM & BWC & DT & BWC $\times$ DT \\
\hline Claudin-3 & 0.578 & 1.000 & 0.471 & 0.546 & 0.17 & 0.086 & 0.126 & 0.279 \\
ZO1 & 0.836 & 1.001 & 0.734 & 0.997 & 0.26 & 0.835 & 0.405 & 0.847 \\
ALP & $4.505^{\mathrm{a}}$ & $1.000^{\mathrm{b}}$ & $0.564^{\mathrm{b}}$ & $2.384^{\mathrm{a}, \mathrm{b}}$ & 1.22 & 0.283 & 0.477 & 0.031 \\
SI & 4.154 & 1.000 & 1.038 & 1.564 & 1.08 & 0.226 & 0.214 & 0.086 \\
EAAC1 & 1.968 & 0.998 & 3.198 & 3.877 & 0.99 & 0.043 & 0.881 & 0.402 \\
B0AT1 & 1.228 & 1.001 & 1.867 & 2.696 & 0.41 & 0.007 & 0.464 & 0.203 \\
PEPT1 & 1.545 & 1.000 & 2.519 & 2.593 & 0.39 & 0.002 & 0.533 & 0.414 \\
SGLT1 & $1.627^{\mathrm{a}, \mathrm{b}}$ & $1.000^{\mathrm{b}}$ & $1.598^{\mathrm{a}, \mathrm{b}}$ & $2.127^{\mathrm{a}}$ & 0.27 & 0.048 & 0.853 & 0.038 \\
ASCT2 & 0.531 & 1.000 & 0.154 & 0.459 & 0.36 & 0.189 & 0.267 & 0.812 \\
\hline
\end{tabular}

ALP; alkaline phosphatase, SI; sucrase-isomaltase, SGLT1; sodium/glucose cotransporter 1, EAAC1; excitatory amino acid transporter 1, ASCT2; glutamine transporter, $\mathrm{B}^{0}$ AT1; neutral amino acid transporter, PepT1; peptide transporter 1, ZO-1; zonula occludens-1, CLDN3; claudin 3, CycA; Cyclophilin-A. LBW; low birth weight, NBW; normal birth weight, RN; restricted nutrition; NN; normal nutrition, BWC; birth weight category, DT; dietary treatment. ${ }^{\mathrm{a}, \mathrm{b}}$ Lowercase letters within a row represent significant treatment interaction $(p<0.05)$.

Table 3. Jejunal nutrient transporter and tight junction mRNA transcript abundance at $56 \mathrm{~d}$ post-weaning.

\begin{tabular}{ccccccccc}
\hline & \multicolumn{2}{c}{ LBW } & \multicolumn{3}{c}{ NBW } & \multicolumn{3}{c}{$p$-Value } \\
\hline Genes & RN & NN & RN & NN & SEM & BWC & DT & BWC $\times$ DT \\
\hline Claudin 3 & 0.952 & 1.510 & 0.250 & 2.171 & 0.37 & 0.955 & 0.002 & 0.075 \\
ZO1 & 0.596 & 2.098 & 0.420 & 3.293 & 0.52 & 0.338 & $<0.001$ & 0.200 \\
ALP & $0.688^{\mathrm{b}}$ & $7.321^{\mathrm{b}}$ & $0.656^{\mathrm{b}}$ & $20.934^{\mathrm{a}}$ & 3.11 & 0.041 & $<0.001$ & 0.041 \\
SI & $2.594^{\mathrm{b}}$ & $4.977^{\mathrm{b}}$ & $1.097^{\mathrm{b}}$ & $15.718^{\mathrm{a}}$ & 2.28 & 0.052 & $<0.001$ & 0.012 \\
EAAC1 & 0.574 & 1.371 & 1.593 & 1.931 & 0.53 & 0.148 & 0.294 & 0.669 \\
B0AT1 & 1.264 & 2.776 & 0.685 & 4.455 & 0.69 & 0.435 & $<0.001$ & 0.116 \\
PEPT1 & 1.114 & 1.235 & 1.820 & 1.150 & 0.49 & 0.532 & 0.581 & 0.427 \\
SGLT1 & 0.679 & 0.552 & 0.595 & 0.971 & 0.20 & 0.413 & 0.539 & 0.222 \\
ASCT2 & 0.556 & 1.520 & 0.130 & 3.018 & 0.61 & 0.388 & 0.004 & 0.127 \\
\hline
\end{tabular}

ALP; alkaline phosphatase, SI; sucrase-isomaltase, SGLT1; sodium/glucose cotransporter 1, EAAC1; excitatory amino acid transporter 1, ASCT2; glutamine transporter, $\mathrm{B}^{0}$ AT1; neutral amino acid transporter, PepT1; peptide transporter 1, ZO-1; zonula occludens-1, CLDN3; claudin 3, CycA; Cyclophilin-A. LBW; Low birth weight, NBW; normal birth weight, RN; restricted nutrition; NN; normal nutrition, BWC; birth weight category, DT; dietary treatment. ${ }^{\mathrm{a}, \mathrm{b}}$ Lowercase letters within a row represent significant treatment interaction $(p<0.05)$.

\section{Discussion}

\subsection{Birth Weight and Nutrition Effect on Enzyme Activity}

Enzyme activity in the gut is important in the digestion and absorption of nutrients, therefore, when enzyme activity is downregulated, there is potential for a negative impact on nutrient absorption. Alkaline phosphatase is directly involved in intestinal immune response and, when the expression is reduced, may predispose the gut to changes in the gut microbiome and intestinal inflammation and permeability [20]. Intestinal inflammation has been reported in LBW [5] as well as nutrient-restricted neonatal pigs [21]. In the present 
study, we observed no effect of treatment on ALP activity at d 28, whereas ALP enzyme activity was upregulated in NBW-NN compared to the other groups at $56 \mathrm{~d}$. This may be explained by intestinal protective roles of ALP recently reviewed by Lallès [22], which may indicate improved gastrointestinal health as a result of higher birth weight and neonatal nutrient intake. Huygelen et al. [23] reported no effect of birth weight (low vs. normal) on ALP expression in the small intestine of pigs at weaning, which confirms the findings in the present work showing that neonatal nutrient allowance may improve intestinal ALP activity, particularly in the long-term (e.g., $56 \mathrm{~d}$ post-weaning). Maltase is a brush border enzyme involved in effectively hydrolyzing $\alpha-1,4$ and $\alpha-1,6$ linkages for the digestion of several carbohydrates [24]. Sucrase-isomaltase is also a highly prevalent enzyme for digestion of different dietary carbohydrates, which supports intestinal physiology and immune response [25]. In the present study, we observed no effect of the experimental treatments on maltase or sucrase activities at $28 \mathrm{~d}$, which was consistent with the lack of effect of treatments on SI gene expression. Interestingly, at $56 \mathrm{~d}$, SI activity was upregulated in NN pigs compared to RN pigs, regardless of birth weight. Moreover, it is well known that increased access to milk intake early in life augments gastrointestinal development later in life [26], which may contribute to improved digestion and absorption of carbohydrates. Since the adult pattern of distribution of brush-border carbohydrases is achieved around 8 weeks [27], our findings indicate a better adaptation of NBW-NN pigs to the weaning transition from milk- to cereal-based diet and highlight that neonatal nutrient restriction may play an important role in this establishment.

\subsection{Birth Weight and Nutrition Effect on Target Gene mRNA Transcript Abundance}

In the present study, we observed an upregulation of ALP gene expression in NBWNN pigs compared to other treatments at both d 28 and d 56. Alkaline phosphate is known as a regulator of inflammation and may play an active role in intestinal development in early life [15]. Furthermore, sucrase isomaltase gene expression was observed to be upregulated in the NBW-NN group compared to the other treatments on 56, but on d 28, there was a tendency for higher expression in the LBW-RN pigs. Indeed, a recent study reported expression of SI at 14 times higher in NBW compared to LBW piglets and an increased expression of SI with age in NBW but not in LBW [28]. At $28 \mathrm{~d}$, Claudin-3 tended to be upregulated in NBW compared to LBW pigs, with no effects of treatments on ZO-1 and ASCT2. Conversely, at $56 \mathrm{~d}$, Claudin-3 and ZO-1 were upregulated in NN compared to RN pigs. Our findings suggest an improved intestinal physical barrier in NBW pigs around weaning. Interestingly, intestinal barrier function (Claudin-3 and ZO-1 expression) was influenced by neonatal nutrient allowance and not body weight at $56 \mathrm{~d}$. Tissue stability and barrier function are influenced by tight junction protein function, with higher expression being positively correlated with enhanced barrier function [29]. A previous report indicated that milk/colostrum consumption may further enhance tight junction proteins expression [30], which is in line with our results, which demonstrated increased expression of tight junction proteins in NN pigs. This may relate to increased gut barrier protection and improve the ability of pigs to cope with intestinal disturbances post-weaning [31]. At $28 \mathrm{~d}$, EAAC1 (glutamate transporter; [32]) and B ${ }^{0}$ AT1 (neutral amino acids transporter; [33]) were downregulated in LBW compared to NBW pigs, which is in agreement with previous studies and suggests that intestinal normal absorptive function and mucosal growth may be decreased in LBW pigs due to decreased amino acid availability for protein synthesis $[34,35]$. Conversely, at $56 \mathrm{~d}$, there was no effect of treatment on EAAC1 expression, however, both $\mathrm{B}^{0} \mathrm{AT} 1$ and ASCT2 (glutamine transporter) were downregulated in RN pigs compared to NN pigs, with no influence of birth weight. These findings confirm the lack of an independent effect of birth weight on small intestine development, as we have previously reported [12], which is likely dependent on nutrient intake. Moreover, neutral amino acids, including proline [36] and glycine [37], are nutritionally essential for milk-fed pigs and neonatal nutrient restriction may have decreased expression of their transporters later in life. Peptide transporter 1 (PepT1, di- and tripeptides transporter; [38]) has been 
reported that PepT1 is highly expressed in LBW pigs [39]. However, there is great variability in expression across the different segments of the intestine [40,41], which may explain discrepancies among studies. In the present study, expression of PepT1 was downregulated in LBW compared to NBW pigs at $28 \mathrm{~d}$ and showed no effects at 56 . This observation suggests that birth weight may influence the absorption of nutrients (e.g., amino acids) in neonatal pigs, likely due to reduced capacity of the gut to feed intake and enzyme secretion. Again, the sodium-dependent glucose transporter 1 (SGLT1, sodium-dependent glucose uptake in the small intestine; [42]) was upregulated in NBW-NN compared to LBW-NN pigs at $28 \mathrm{~d}$, with no effects observed at $56 \mathrm{~d}$. The results indicate that, when piglets fed a normal level of nutrients, their birth weight will have an influence on glucose transport capacity; in this case the results show that pigs with NBW have higher glucose transport capacity than LBW pigs. These results are aligned with another study which reported that SGLT1 expression is influenced by feeding but this may be restricted by birth weight [43].

\section{Conclusions}

In summary, our results showed that jejunal gene expression and enzyme activity at $28 \mathrm{~d}$ and 56 were associated with differences in both birthweight and nutrition, with reduced expression of amino acid transporters in LBW compared to NBW pigs. Further, normal birth weight and normal nutrition pigs had upregulated expression of target genes and greater enzyme activity compared to the other groups, indicating that intestinal development may be influenced by both birth weight and nutrition.

Author Contributions: D.A.C., M.O.W., L.A.R. and C.Y. designed the study, M.O.W. and L.A.R. conducted the study, Q.L. and B.D. conducted the lab analysis, M.O.W., L.A.R. and J.C.P. analyzed the data and wrote the manuscript. All authors have read and agreed to the published version of the manuscript.

Funding: Funding for this project was provided by the Natural Sciences and Engineering Research Council of Canada (RGPIN-2017-05275).

Institutional Review Board Statement: The experimental protocols were approved by the University of Saskatchewan's Animal Research Ethics Board under protocols 20190042 and followed Canadian Council on Animal Care guidelines.

Data Availability Statement: Data are available from the corresponding author upon reasonable request.

Acknowledgments: The authors would like to thank the staff at the Prairie Swine Centre, Inc., and Dylan Olver, and Lynn Weber (Department of Veterinary Biomedical Sciences the Western College of Veterinary Medicine) for technical support.

Conflicts of Interest: All authors declare no conflict of interest, financial or otherwise.

\section{References}

1. Quesnel, H.; Brossard, L.; Valancogne, A.; Quiniou, N. Influence of some sow characteristics on within-litter variation of piglet birth weight. Animal 2008, 2, 1842-1849. [CrossRef] [PubMed]

2. Kapell, D.N.R.G.; Ashworth, C.J.; Knap, P.W.; Roehe, R. Genetic parameters for piglet survival, litter size and birth weight or its variation within litter in sire and dam lines using bayesian analysis. Livest. Sci. 2011, 135, 215-224. [CrossRef]

3. Campbell, R.G.; Dunkin, A.C. The effect of birth weight on the estimated milk intake, growth and body composition of sow-reared piglets. Anim. Sci. 1982, 35, 193-197. [CrossRef]

4. Cabrera, R.A.; Lin, X.; Campbell, J.M.; Moeser, A.J.; Odle, J. Influence of birth order, birth weight, colostrum and serum immunoglobulin g on neonatal piglet survival. J. Anim. Sci. Biotechnol. 2012, 3, 42. [CrossRef] [PubMed]

5. Tao, S.; Bai, Y.; Li, T.; Li, N.; Wang, J. Original low birth weight deteriorates the hindgut epithelial barrier function in pigs at the growing stage. FASEB J. 2019, 33, 9897-9912. [CrossRef] [PubMed]

6. Michiels, J.; Vos, M.D.; Missotten, J.; Ovyn, A.; Smet, S.D.; Ginneken, C.V. Maturation of digestive function is retarded and plasma antioxidant capacity lowered in fully weaned low birth weight piglets. Br. J. Nutr. 2013, 109, 65-75. [CrossRef]

7. Milligan, B.; Fraser, D.; Kramer, D. The effect of littermate weight on survival, weight gain, and suckling behavior of low-birthweight piglets in cross-fostered litters. Ontog. Collect. 2001, 9, 161-168. 
8. Souza, L.P.; Fries, H.C.C.; Heim, G.; Faccin, J.E.; Hernig, L.F.; Marimon, B.T.; Bernardi, M.L.; Bortolozzo, F.P.; Wentz, I. Behaviour and growth performance of low-birth-weight piglets cross-fostered in multiparous sows with piglets of higher birth weights. Arq. Bras. Med. Vet. E Zootec. 2014, 66, 510-518. [CrossRef]

9. $\quad$ Spreeuwenberg, M.A.M.; Verdonk, J.M.A.J.; Gaskins, H.R.; Verstegen, M.W.A. Small intestine epithelial barrier function is compromised in pigs with low feed intake at weaning. J. Nutr. 2001, 131, 1520-1527. [CrossRef] [PubMed]

10. Farhadi, A.; Banan, A.; Fields, J.; Keshavarzian, A. Intestinal barrier: An interface between health and disease. J. Gastroenterol. Hepatol. 2003, 18, 479-497. [CrossRef]

11. Stewart, A.S.; Pratt-Phillips, S.; Gonzalez, L.M. Alterations in intestinal permeability: The role of the "Leaky Gut" in health and disease. J. Equine Vet. Sci. 2017, 52, 10-22. [CrossRef]

12. Rodrigues, L.A.; Wellington, M.O.; Sands, J.M.; Weber, L.P.; Olver, T.D.; Ferguson, D.P.; Columbus, D.A. Characterization of a swine model of birth weight and neonatal nutrient restriction. Curr. Dev. Nutr. 2020, 4, nzaa116. [CrossRef]

13. Beaulieu, A.D.; Aalhus, J.L.; Williams, N.H.; Patience, J.F. Impact of piglet birth weight, birth order, and litter size on subsequent growth performance, carcass quality, muscle composition, and eating quality of pork. J. Anim. Sci. 2010, 88, 2767-2778. [CrossRef]

14. Berkeveld, M.; Langendijk, P.; van Beers-Schreurs, H.M.G.; Koets, A.P.; Taverne, M.a.M.; Verheijden, J.H.M. Postweaning growth check in pigs is markedly reduced by intermittent suckling and extended lactation. J. Anim. Sci. 2007, 85, 258-266. [CrossRef] [PubMed]

15. Kuller, W.I.; Soede, N.M.; van Beers-Schreurs, H.M.G.; Langendijk, P.; Taverne, M.A.M.; Kemp, B.; Verheijden, J.H.M. Effects of intermittent suckling and creep feed intake on pig performance from birth to slaughter. J. Anim. Sci. 2007, 85, 1295-1301. [CrossRef]

16. Engström, L. Studies on bovine-liver alkaline phosphatase, purification, phosphate incorporation. Biochim. Biophys. Acta BBA-Spec. Sect. Enzymol. Subj. 1964, 92, 71-78. [CrossRef]

17. Hübscher, G.; West, G.R. Specific assays of some phosphatases in subcellular fractions of small intestinal mucosa. Nature 1965, 205, 799-800. [CrossRef] [PubMed]

18. Dahlqvist, A. Method for assay of intestinal disaccharidases. Anal. Biochem. 1964, 7, 18-25. [CrossRef]

19. Livak, K.J.; Schmittgen, T.D. Analysis of relative gene expression data using real-time quantitative PCR and the $2-\Delta \Delta C T$ method. Methods 2001, 25, 402-408. [CrossRef] [PubMed]

20. Bilski, J.; Mazur-Bialy, A.; Wojcik, D.; Zahradnik-Bilska, J.; Brzozowski, B.; Magierowski, M.; Mach, T.; Magierowska, K.; Brzozowski, T. The role of intestinal alkaline phosphatase in inflammatory disorders of gastrointestinal tract. Mediat. Inflamm. 2017, 2017, e9074601. [CrossRef] [PubMed]

21. Maga, E.A.; Weimer, B.C.; Murray, J.D. Dissecting the role of milk components on gut microbiota composition. Gut Microbes 2013, 4, 136-139. [CrossRef]

22. Lallès, J.-P. Intestinal alkaline phosphatase: Novel functions and protective effects. Nutr. Rev. 2014, 72, 82-94. [CrossRef]

23. Huygelen, V.; De Vos, M.; Willemen, S.; Fransen, E.; Casteleyn, C.; Van Cruchten, S.; Van Ginneken, C. Age-related differences in mucosal barrier function and morphology of the small intestine in low and normal birth weight piglets1. J. Anim. Sci. 2014, 92, 3398-3406. [CrossRef] [PubMed]

24. Lee, B.-H.; Hamaker, B.R. Maltase has most versatile $\alpha$-Hydrolytic activity among the mucosal $\alpha$-Glucosidases of the small intestine. J. Pediatr. Gastroenterol. Nutr. 2018, 66, S7. [CrossRef] [PubMed]

25. Gericke, B.; Amiri, M.; Naim, H.Y. The multiple roles of sucrase-isomaltase in the intestinal physiology. Mol. Cell. Pediatr. 2016, 3 , 2. [CrossRef] [PubMed]

26. Kramer, M.S.; Kakuma, R. The optimal duration of exclusive breastfeeding: A systematic review. Adv. Exp. Med. Biol. 2004, 554, 63-77.

27. Kidder, D.E.; Manners, M.J. The level and distribution of carbohydrases in the small intestine mucosa of pigs from 3 weeks of age to maturity. Br. J. Nutr. 1980, 43, 141-153. [CrossRef]

28. Ayuso, M.; Irwin, R.; Walsh, C.; Cruchten, S.V.; Ginneken, C.V. Low birth weight female piglets show altered intestinal development, gene expression, and epigenetic changes at key developmental loci. FASEB J. 2021, 35, e21522. [CrossRef] [PubMed]

29. Chiba, H.; Osanai, M.; Murata, M.; Kojima, T.; Sawada, N. Transmembrane proteins of tight junctions. Biochim. Biophys. Acta BBA-Biomembr. 2008, 1778, 588-600. [CrossRef] [PubMed]

30. Grześkowiak, Ł.; Martínez-Vallespín, B.; Dadi, T.H.; Radloff, J.; Amasheh, S.; Heinsen, F.-A.; Franke, A.; Reinert, K.; Vahjen, W.; Zentek, J.; et al. Formula feeding predisposes neonatal piglets to clostridium difficile gut infection. J. Infect. Dis. 2018, 217, 1442-1452. [CrossRef] [PubMed]

31. Grześkowiak, Ł.; Pieper, R.; Kröger, S.; Martínez-Vallespín, B.; Hauser, A.E.; Niesner, R.; Vahjen, W.; Zentek, J. Porcine colostrum protects the IPEC-J2 cells and piglet colon epithelium against clostridioides (Syn. Clostridium) difficile toxin-induced effects. Microorganisms 2020, 8, 142. [CrossRef] [PubMed]

32. Fan, M.Z.; Matthews, J.C.; Etienne, N.M.P.; Stoll, B.; Lackeyram, D.; Burrin, D.G. Expression of apical membrane L-glutamate transporters in neonatal porcine epithelial cells along the small intestinal crypt-villus axis. Am. J. Physiol.-Gastrointest. Liver Physiol. 2004, 287, G385-G398. [CrossRef] [PubMed]

33. Kanai, Y.; Hediger, M.A. The glutamate and neutral amino acid transporter family: Physiological and pharmacological implications. Eur. J. Pharmacol. 2003, 479, 237-247. [CrossRef] 
34. Yang, H.; Fu, D.; Shao, H.; Kong, X.; Wang, W.; Yang, X.; Nyachoti, C.M.; Yin, Y. Impacts of birth weight on plasma, liver and skeletal muscle neutral amino acid profiles and intestinal amino acid transporters in suckling Huanjiang mini-piglets. PLoS ONE 2012, 7, e50921. [CrossRef] [PubMed]

35. Fu, D.; Yang, H.; Kong, X.; Blachier, F.; Wang, W.; Yin, Y. Molecular cloning and expression profiling of excitatory amino acid carrier 1 in suckling huanjiang mini-piglets with large or small body weight at birth. Mol. Biol. Rep. 2013, 40, 3341-3350. [CrossRef]

36. Ball, R.O.; Atkinson, J.L.; Bayley, H.S. Proline as an essential amino acid for the young pig. Br. J. Nutr. 1986, 55, 659-668. [CrossRef]

37. Wang, W.; Dai, Z.; Wu, Z.; Lin, G.; Jia, S.; Hu, S.; Dahanayaka, S.; Wu, G. Glycine is a nutritionally essential amino acid for maximal growth of milk-fed young pigs. Amino Acids 2014, 46, 2037-2045. [CrossRef] [PubMed]

38. Newstead, S. Recent advances in understanding proton coupled peptide transport via the POT family. Curr. Opin. Struct. Biol. 2017, 45, 17-24. [CrossRef]

39. D'Inca, R.; Guen, C.G.-L.; Che, L.; Sangild, P.T.; Huërou-Luron, I.L. Intrauterine growth restriction delays feeding-induced gut adaptation in term newborn pigs. Neonatology 2011, 99, 208-216. [CrossRef] [PubMed]

40. Thongsong, B.; Suthongsa, S.; Wiyaporn, M. Postnatals ontogeny of small intestinal histomorphology, crypt cell proliferation and peptide transporter 1 gene expression in piglets. Thai J. Vet. Med. 2016, 46, 391-399.

41. Thongsong, B.; Wiyaporn, M.; Kalandakanond-Thongsong, S. Blood glucose, amino acid profiles and nutrient transporter gene expressions in the small intestine of low and normal birthweight piglets during the early suckling period. Vet. J. 2019, 247, 1-7. [CrossRef] [PubMed]

42. Poulsen, S.B.; Fenton, R.A.; Rieg, T. Sodium-Glucose cotransport. Curr. Opin. Nephrol. Hypertens. 2015, 24, 463-469. [CrossRef] [PubMed]

43. Sangild, P.T.; Petersen, Y.M.; Schmidt, M.; Elnif, J.; Petersen, T.K.; Buddington, R.K.; Greisen, G.; Michaelsen, K.F.; Burrin, D.G. Preterm birth affects the intestinal response to parenteral and enteral nutrition in newborn pigs. J. Nutr. 2002, 132, 2673-2681. [CrossRef] [PubMed] 